\title{
ÉTICA NA ADMINISTRAÇÃO CONTEMPORÂNEA: SERIA ESTA UMA QUESTÃO?
}

ETHICS IN CONTEMPORARY MANAGEMENT: IS THIS A QUESTION?

\author{
Lydia Maria Pinto Brito ${ }^{1}$ \\ Ricardo Sérgio Gomes Vieira ${ }^{2}$
}

\section{RESUMO}

A partir do texto "Ético: Ser ou não ser? Seria esta uma questão?" publicado nos Anais do Enanpad 2006, existe uma discussão se realmente pode haver ética nos relacionamentos de marketing em um ambiente concorrencial no qual as organizações estão inseridas. Neste artigo, trataremos da ética não como um pressuposto para a construção de relacionamentos de negócios, como aconteceu no artigo mencionando, mas na maneira como ela tende a ser entendida pelos atores organizacionais. Questionamo-nos, fundamentado pelos conceitos de ética da filosofia clássica e moderna, se é possível o exercício da ética dentro do modelo capitalista de produção? O que está se convencionando chamar de ética na Administração não seria uma moral datada histórica e espacialmente? Existe uma "ética" que não seja social? Os conceitos de Administração dão conta dos problemas gerados no campo de sua própria ação? Inferimos que os respondentes percebem a importância da moral, por eles nomeada de ética, entretanto, acreditamos ser necessário melhor compreensão do real significado e dimensão para a Administração contemporânea deste termo. Aqui reside o objetivo deste ensaio.

Palavras-chave: Ética - Ética Weberiana - Ética Marxista.

\section{ABSTRACT}

From the text "Ethics: To be or not to be? Is this a question? "Published in the Proceedings of Enanpad 2006 there was actually a discussion can be ethical marketing relationships in a competitive environment in which organizations are embedded. In this article, we address the ethics not as a prerequisite to building business relationships, as in the article mentioning, but the way it tends to be understood by organizational actors. We wondered, founded by the ethical concepts of classical and modern philosophy, it is possible the exercise of ethics within the capitalist mode of production? What is with the convention call ethics in management would not be a moral dated historical and spatially? There is an "ethical" than social? The concepts of Directors aware of the problems generated in the field of their own action? We infer that respondents perceive the importance of morale, which they named ethics, however, we believe it is necessary to better understand the real meaning and dimension to the contemporary management of this term. Herein lies the purpose of this essay.

Keywords: Ethics - Weberian ethics - Marxist ethics. 


\section{INTRODUÇÃO}

Como bem lembra (VIEIRA, 2006) as questões éticas e morais vem sendo consideradas cada vez mais relevantes para o entendimento da construção de relacionamentos de negócios. Ao que parece, na sociedade contemporânea e nos mercados e organizações que nela estão inseridos, a moral não é mais considerada algo periférico na geração e desenvolvimento dos relacionamentos interorganizacionais. Ao invés disso, é apontada como um dos pilares do existir destas interações (cf. CHONKO e HUNT, 1985; HUNT e VITELL, 1986; KAVALI, TZOKAS e SAREN, 1999). Em seu cotidiano de negócios os atores organizacionais se envolvem com dilemas e questões éticas associados aos julgamentos relacionados às finalidades últimas das ações. Contemplar e observar o aparecimento de questões éticas e morais em suas pesquisas focalizadas no cotidiano de negócios de atores organizacionais já vem sendo o objetivo de alguns acadêmicos (e.g., KELLER e MACHADO, 2006; FOURNIER e YAO, 1997). Apesar de Vieira (2006) apontar que o interesse por este termo se deve as fortes evidências de que a formação teórica de tais relacionamentos possui raízes nos princípios e conceitos éticos e morais, tais como: noção de benefícios mútuos e recíprocos, os quais estão em consonância com as teorias que versam sobre lealdade, percepção de justiça e confiança mútua entre os parceiros (i.e., indivíduos interagentes) (cf. GUNDLACH e MURPHY, 1993; MURPHY, WOOD e LACKZINIAC, 1996; TAKALA e UUSITALO, 1996), numa maneira mais ampla podemos citar a emergência das questões ecológicas e o compartilhamento da responsabilidade pelo futuro do planeta como pauta de relações políticas, econômicas e de negócio internacionais.

Ao final de seu trabalho, o autor afirma que surgiram mais perguntas do que respostas. Ele alega que ouviu por inúmeras vezes a importância percebida pelo ator organizacional de ser ético e que isto é considerada por eles como condição fundamental para a construção de relacionamentos, mas questiona 0 real significado deste termo significa para estes atores interagentes. Em outras palavras, não ficou claro o que é entendido pelos empreendedores de empresas de base tecnológica o que significa ser uma pessoa ética. Por esta razão ele indica a necessidade de revisitar este tema 
com mais profundidade. Resgatando o referencial de análise que possibilitou a este autor pontuar e interpretar as falas dos pesquisados, iremos utilizar neste trabalho o conceito de ética e moral da filosofia clássica e moderna; a abordagem compreensiva weberiana; e a abordagem crítica marxista.

Assim, este estudo se fundamenta em autores da área de negócios e marketing e tem como referencial de análise os conceitos de ética da filosofia clássica e moderna (ARISTÓTELES, 2005 e KANT, cf. VANCOURT, 1987), na identificação do confronto entre os pressupostos subjacentes aos relacionamentos a partir de: (A) da análise compreensiva de Weber (1959), autor fundante do pensamento da Administração, mediante a utilização das teorias de ética da convicção e ética da responsabilidade; e (B) da análise do materialismo dialético de um autor crítico do modelo capitalista, representado por Marx (1982) a partir das categorias de trabalho, totalidade, sociedade de classes e materialismo histórico. As perguntas de partida que orientaram este ensaio estudo consistem: é possível o exercício da ética dentro do modelo capitalista de produção? O que está se convencionando chamar de ética na Administração não seria uma moral datada histórica e espacialmente? Existe uma "ética" que não seja social? Os conceitos de Administração de Marketing dão conta dos problemas gerados no campo de sua própria ação.

Ainda assim, embora se possa supor que os relacionamentos e interações de negócios estejam imbricados em princípios éticos, poucas tem sido as pesquisa empíricas que objetivaram compreender o significado das ações éticas e morais presentes nas relações entre estes atores organizacionais. Mesmo porque se pressupõe que é um tema já estudado e que faz parte do composto de confiança. Assim, na intenção de trazer á tona esta discussão, este artigo tem por objetivo explorar o real significado e dimensão para a Administração contemporânea do termo Ética.

\section{QUE É ÉTICA E MORAL?}

Aristóteles (2005) classificava os campos do saber em: ciências produtivas - que estudam as práticas produtivas e as técnicas, como a arquitetura, a economia e a medicina, e por que não dizer, em termos de hoje, a administração; as ciências teoréticas ou contemplativas - que estudam coisas que existem independentemente dos homens e de suas ações como, 
por exemplo, a física e a biologia; e as ciências práticas - que estudam as práticas humanas enquanto ações que têm nelas mesmas seu próprio fim. É nesta última categoria que se enquadraria a Ética. Desta forma, caberia a Filosofia: o conhecimento do SER ou ontologia; o conhecimento da capacidade humana de conhecer exercitado pela lógica e pela ciência; e o conhecimento das ações humanas ou dos valores e das finalidades da ação humana, tais como aquelas que têm em si mesmas sua finalidade como a ética, a política e a vida moral e as ações que têm finalidade numa obra como a arte.

Assim, a ética para a filosofia clássica, faz parte do exercício de filosofar, enquanto dimensão que busca a finalidade última das coisas e dos seres, e que consiste em toda arte e toda investigação, bem como toda ação e toda escolha que tem objetivo o bem, o melhor, o sumo bem universal que beneficiaria o conjunto da sociedade na conquista da felicidade. A ética é, portanto, parte da filosofia que aborda, analisa e critica a partir de valores universais os fundamentos e os princípios da moral.

Já a moral seria a ciência do bem e do mal, ou seja, a teoria do comportamento humano que varia de cultura para cultura e se modifica no tempo e/ou no espaço e/ou no âmbito de uma mesma sociedade. É um corpo de preceitos e regras que visa a dirigir as ações humanas segundo os princípios de justiça e equidade natural.

$\mathrm{Na}$ Filosofia Moderna, Kant (VANCOURT, 1987) de acordo com Aristóteles, entende que os problemas éticos caracterizam-se pela sua universalidade, enquanto que os morais se apresentam nas situações concretas da vida cotidiana. A moral significa etimologicamente costume, no sentido de conjunto de normas ou regras adquiridas por hábito, correspondendo assim, aos eventos da vida cotidiana que dizem respeito à conduta subjetiva. A ética é uma disciplina normativa (teoria) que tem como objetivo explicar, esclarecer ou investigar em determinada realidade os princípios, regras e valores que devem regular a ação humana, tendo em vista a sua harmonia, visando elaborar os conceitos correspondentes, com a função de indicar o melhor comportamento do ponto de vista moral. Para tal, a ética eleva os seus princípios e as suas normas à categoria dos princípios e normas universais, válidos para qualquer moral, apesar desta ser dinâmica e mutável com o tempo. 
Assim, a moral é entendida como um sistema de valores e princípios, das prescrições admitidas, de normas (dotadas de caráter histórico e social) que uma dada sociedade regulamenta ao longo das épocas por meio de relações mútuas entre atores, ou entre esses e a comunidade (OLIVEIRA, 1996). Desta forma, para Kant, uma lei moral pode ser generalizada e atingir a condição de lei ética, desde que a primeira possa ser aplicada a todos os "seres" dotados de razão (imperativo categórico). Isso significa dizer que tal lei moral (elevada à categoria ética) provém de princípios universais, não podendo, dessa forma, ser fruto da experiência, posto que pudesse ser considerada uma lei particular, passível de ser relativizada e, sendo assim, apenas uma regra social. Portanto, ética e moral podem ser tomadas enquanto instâncias intercambiáveis. (DIAS, 2002; OLIVEIRA, 1996) já que a Ética, por sua dimensão filosófica, faz a crítica da moral.

\section{ANÁLISE COMPREENSIVA DE WEBER}

Para Weber (SROUR, 2003), um dos autores fundante do pensamento da Administração, existem dois tipos de teorias éticas: Ética da Convicção, entendida como deontologia (tratado de deveres) que se pauta por valores e normas previamente estabelecidos, cujo efeito primeiro consiste em moldar as ações que deverão ser praticadas; e a Ética da Responsabilidade, conhecida como teleologia (estudo dos fins humanos) quando os agentes realizam uma análise da situação e avaliam os efeitos que a ação produz, planejam resultados positivos para a coletividade e ampliam o leque das escolhas.

A Ética da Convicção tem duas Vertentes: de princípio - que se atém rigorosamente às regras pré-estabelecidas, com desinteresse pelas circunstâncias; e a da esperança que é ancorada em ideais.

Já a Ética da Responsabilidade tem como foco a decisão e deriva de uma reflexão sobre as implicações que cada possível curso de ação apresenta; obriga-se ao conhecimento das circunstâncias vigentes; configura uma análise de riscos; supõe uma análise de custo e benefícios; e funda-se sempre na presunção de que serão alcançados conseqüências ou fins muito valiosos, porque altruístas e imparciais. Suas Vertentes são: Utilitarista - exige que as 
ações produzam o máximo de bem para o maior número de pessoas; e Da finalidade - determina que a bondade dos fins justifica as ações empreendidas.

Quadro 1- As duas teorias éticas

\begin{tabular}{|l|l|}
\hline \multicolumn{1}{|c|}{$\begin{array}{c}\text { Ética da Responsabilidade - } \\
\text { (estudo dos fins humanos) }\end{array}$} & $\begin{array}{c}\text { Ética da Convicção - Deontologia } \\
\text { (tratado dos deveres) }\end{array}$ \\
\hline $\begin{array}{l}\text { É uma ética dos propósitos, da razão, } \\
\text { dos resultados previsíveis, dos } \\
\text { prognósticos, das análises de } \\
\text { circunstâncias, dos fatores } \\
\text { condicionantes. }\end{array}$ & $\begin{array}{l}\text { É uma ética dos deveres das } \\
\text { obrigações de consciência, das } \\
\text { certezas, dos imperativos categóricos, } \\
\text { das ordenações incondicionais. }\end{array}$ \\
\hline $\begin{array}{l}\text { Corresponde a um realismo pragmático- } \\
\text { analítico, calculista, indutivo, pluralista, } \\
\text { flexível. }\end{array}$ & $\begin{array}{l}\text { Corresponde a um idealismo purista - } \\
\text { dogmático, lírico, dedutivo, maniqueísta, } \\
\text { rígido. }\end{array}$ \\
\hline $\begin{array}{l}\text { Ética situacional e condicional, moldada } \\
\text { pelo ceticismo e pelas análises de risco }\end{array}$ & $\begin{array}{l}\text { Ética convencional e incondicional, com } \\
\text { aspecto de catecismo ou cartilha. }\end{array}$ \\
\hline $\begin{array}{l}\text { Enfrenta a vertigem das perguntas e o } \\
\text { desafio das soluções relativistas. }\end{array}$ & $\begin{array}{l}\text { Repousa no conforto das respostas } \\
\text { acabadas e das verdades absolutas. }\end{array}$ \\
\hline $\begin{array}{l}\text { Correntes: Utilitarismo e a Ética de } \\
\text { Virtudes }\end{array}$ & $\begin{array}{l}\text { Correntes: Ética do Dever, Ética do } \\
\text { Discurso e o Contratualismo Moral. }\end{array}$ \\
\hline
\end{tabular}

Fonte - Adaptado de Srour (2003,p.140)

Alinhadas a cada uma destas macro-vertentes orbitam diversas concepções éticas cuja análise um pouco mais acurada pode auxiliar no entendimento da forma como os parceiros julgam o que é moralmente certo ou errado, bem como na compreensão do agir cotidiano. Assim, no rol das perspectivas teleológicas podemos destacar o Utilitarismo e a Ética de Virtudes. Na esfera deontológica, salientamos a Ética do Dever, a Ética do Discurso e o Contratualismo Moral.

Quadro 2 - Essência de cada Sub-corrente das teorias da Ética

\begin{tabular}{|l|l|l|l|}
\hline \multicolumn{1}{|c|}{ Ética da Responsabilidade - Teleologia } \\
\hline Utilitarismo & $\begin{array}{l}\text { Cada parceiro age de modo } \\
\text { a proporcionar o maior bem } \\
\text { ou a maior felicidade para } \\
\text { todos que o cercam. }\end{array}$ & Ética do Dever & $\begin{array}{l}\text { Etuação de acordo com } \\
\text { determinadas regras do } \\
\text { que é certo, } \\
\text { independentemente } \\
\text { disto trazer ou não o } \\
\text { bem estar a um, ou a } \\
\text { todos. }\end{array}$ \\
\hline $\begin{array}{l}\text { Ética de } \\
\text { Virtudes }\end{array}$ & $\begin{array}{l}\text { Os sujeitos compreendem } \\
\text { as qualidades morais que } \\
\text { devem ser dotados para } \\
\text { agir eticamente. }\end{array}$ & $\begin{array}{l}\text { Ética do } \\
\text { Discurso }\end{array}$ & $\begin{array}{l}\text { Julgamento submetido } \\
\text { às normas, mediante um } \\
\text { processo } \\
\text { comunicacional } \\
\text { fundamentado em } \\
\text { argumentos racionais. }\end{array}$ \\
\hline
\end{tabular}




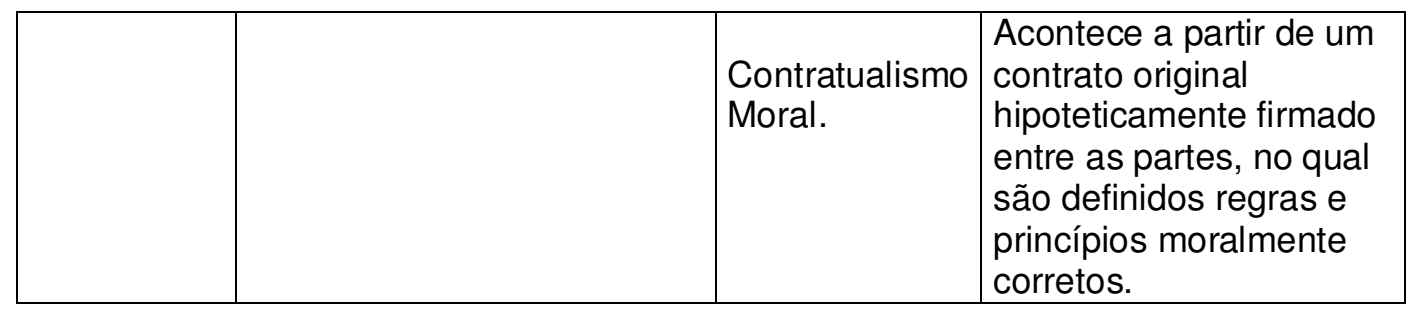

Fonte - elaboração dos autores

\section{1 ÉTICA DA RESPONSABILIDADE}

Sob a perspectiva do Utilitarismo, cada parceiro age de modo a proporcionar o maior bem ou a maior felicidade para todos que o cercam, pois todos os sujeitos são iguais [sistema ético igualitário] e o bem pessoal não prevalece sobre o universal. Assim, as conseqüências das ações são tomadas como medida do que seja certo ou errado, sendo as ações consideradas moralmente corretas na proporção em que constituem meios para alcançar o bem estar do maior número possível de parceiros (cf. TAKALA e UUSITALO, 1996).

Avaliações de parceiros relacionais também podem ser pautadas pela Ética de Virtudes. Nessa concepção, uma ação é correta se levar em consideração o que um agente de caráter virtuoso faria naquela circunstância. Ao deixarem de lado as regras de ação particulares e buscarem a excelência moral e a retidão, os parceiros se concentram no seu modo de viver (não só no relacionamento), no seu modo de ser (i.e., na totalidade de sua existência), procurando então a compreensão das qualidades morais que devem ser dotados para agir eticamente, ou seja, para agir da forma correta, no momento correto e com o sentimento correto. A "doutrina da virtude" apresenta a felicidade dos outros como um fim da ação moral que é, ao mesmo tempo, um dever. Essa finalidade origina deveres em relação aos outros, entre os quais se incluem os deveres de respeito, de beneficência, de gratidão e de simpatia (BORGES, DALL'AGNOL e DUTRA, 2003). Desta forma, a busca pelo caráter virtuoso, por parte de todos os parceiros, contribui positivamente para a manutenção e desenvolvimento dos vínculos que eles estabeleceram entre si. 


\section{2 ÉTICA DA CONVICÇÃO}

Assumindo a perspectiva da Ética do Dever, os parceiros tomam como ações moralmente corretas, aquelas que estejam de acordo com determinadas regras do que é certo, independentemente disto trazer ou não o bem estar a um, ou a todos. Mais do que enfocar as conseqüências da ação, essa perspectiva claramente se concentra na validade moral da intenção dos parceiros relacionais. Desse modo, tendo por base a noção Kantiana do imperativo categórico, a ação é moral se a regra da ação puder ser tomada como regra universal, ou seja, se puder ser observada e seguida por todos os seres racionais, sem contradição (HOSMER, 1995). Nesta perspectiva é inumana e indigna a um ser racional, a manipulação do outro para que ele se adapte aos seus desejos. Portanto, é perfeitamente aplicável o principio da fórmula da humanidade, pois, trata-se de respeitar os outros como pessoas, de considerá-los como o fim mesmo de uma ação, e nunca apenas como meio que sirva a outra finalidade. $O$ valor da pessoa deve ser respeitado mediante consentimento nas práticas sociais, afetivas, econômicas ou sexuais de que toma parte. (BORGES, DALL'AGNOL e DUTRA, 2003). O conceito de dever moral, intimamente associado à justiça, nos parece estar intrinsecamente relacionado com o de empatia e de alteridade (MORAES, 2001), haja vista que esses conceitos têm por essência a habilidade dos parceiros da relação em perceberem determinada situação assumindo a perspectiva do outro. Para entender esse dever nos relacionamentos entre os atores organizacionais, fazse necessário compreender o que vem a ser liberdade e responsabilidade moral, pois elas são fundamentos da moralidade.

A justiça não se resume apenas ao aspecto das contribuições (normas), pois ela diz respeito também à distribuição de bens e condições que afetam o bem-estar dos parceiros relacionais (MESSICK e COOK, 1983). Nesse sentido, essa justiça faz-se existente em qualquer situação, em que há um relacionamento. A norma de igualdade ao ser aplicada pelos parceiros relacionais quando eles crêem que os sujeitos envolvidos em uma dada relação devem obter resultados similares independentemente das suas diferentes contribuições ou necessidades. De acordo com essa perspectiva, não importa se uma das partes realiza maiores ou menores esforços 
(comparativamente falando), no fim, os ganhos devem ser divididos igualmente (cf. GREENBERG e MCCARTHY, 1990). A percepção de eqüidade no nível de comparação de alternativas pode e tende a influenciar positiva ou negativamente a intenção da marca ou do consumidor na repetição ou aprofundamento de uma interação [atividade], pois afeta a satisfação deles (ver HOLMLUND, 2000).

Posto que, de um modo geral, podemos alegar que a justiça envolve a adequação de decisões. As teorias que lidam com o conceito de justiça passam a fornecer valiosos subsídios para a compreensão das avaliações dos processos e resultados de uma interação entre a marca e o consumidor (cf. AUSTIN, 1979; FOLGER e GREENBERG, 1985). Diferentemente da reciprocidade, que focaliza a preocupação de oferecer algo que seus parceiros valorizem, a eqüidade no relacionamento está associada à percepção de "equilíbrio" entre o que cada uma das partes oferece e recebe. Assim, a eqüidade não significa igualdade (OLIVER e SWAN, 1989), mas uma percepção de um contexto no qual aquilo que uma parte recebe deve ser proporcional ao esforço empreendido.

Cada um deve ser livre (i.e., deve possuir vontade autônoma) para, sob sua própria tutela, seguir o seu projeto racional de vida, usando essa liberdade para não apenas discernir o bem do mal, mas para agir em função de máximas que a sua consciência moral determine como válidas (DIAS, 2002). Embora exista a liberdade de escolha, essa liberdade em si implica não apenas que o ator tenha consciência de discernir o bem do mal, mas, sobretudo, tenha a possibilidade de agir em função de valores que ele próprio escolha, já que não há comportamento moral sem alguma liberdade. Nesse sentido, o ator é responsável pelas suas decisões e, portanto, pelas conseqüências delas. Portanto, um ato moral pressupõe um sujeito dotado de uma consciência moral, isto é, um "ser" cuja consciência é capaz de distinguir o bem do mal, de orientar os seus atos e julgá-los segundo o seu valor. Essa consciência implica que o sujeito ultrapasse uma dimensão meramente egoísta na sua conduta, tornando-se um cidadão com responsabilidade moral, pois o outro deve ser sempre levado em conta na sua ação moral. Os princípios morais, então, são normas que orientam e fundamentam a sua conduta, posto que sejam assumidos como os mais adequados para a harmonia do "nós" e a felicidade 
individual. Uma vez definidos livremente estes princípios certos atos passam a ser assumidos como obrigações interiores, ou seja, o que o dever moral dita tende a ser cumprido por todos os sujeitos relacionais, em todos os tempos e em todas as circunstâncias e condições (cf. DIAS, 2002).

Uma outra dimensão da justiça é aquela relacionada às interações. Esta é relativa à qualidade do tratamento interpessoal que os indivíduos recebem durante a dinâmica relacional, neste sentido, ela introduz um aspecto comunicacional (BIES e MOAG, 1986) e explica porque alguns parceiros podem se sentir injustiçados apesar de caracterizarem o procedimento de tomada de decisão e o resultado como justos (BIES e SHAPIRO, 1987). Vários têm sido os aspectos identificados como centrais na avaliação dessa justiça, dentre eles, o fornecimento de explicações, a honestidade e a cortesia (BITNER, BOOMS e TETREAULT, 1990).

Sob a perspectiva da Ética Discursiva, são válidas as normas de ação que puderem encontrar consenso no tempo e em circunstâncias particulares de todos os participantes de um discurso prático que, se submetem às normas, mediante argumentos racionais que não conclamem determinações estranhas (e.g., poder, dinheiro) ao processo comunicacional. Está implícita, aqui, a possibilidade dos parceiros chegarem a um acordo mediante a utilização efetiva dos mecanismos de comunicação livres de dominação (TAKALA e UUSITALO, 1996), baseada, fundamentalmente, em uma interpretação intersubjetiva (i.e., processual, dialógica e consensual) da noção kantiana do imperativo categórico. Assim, ao invés de dialogar interiormente consigo mesmo para intuir o que é moralmente correto, sem que as conseqüências das ações sejam levadas em consideração nesse diálogo (i.e., monólogo), o ator organizacional se engaja em uma dinâmica discursiva (i.e., argumentativa) junto a outros elementos de sua rede social para descobrir o que é bom e necessário para todos. Nessa ocasião, ele realiza reflexões relativas às conseqüências das ações no plano coletivo (ROHDEN, 1981). Ao final desse processo discursivo, cada um destes atores organizacionais se convence que, de acordo com as circunstâncias, uma determinada norma de ação é boa e justificável para todos os envolvidos. Assim, a noção do que é certo e errado é construído por meio de dinâmica dialógica entre os parceiros envolvidos em determinado relacionamento de marketing. 
No Contratualismo Moral, a determinação das linhas de ação no relacionamento acontece a partir de um contrato original hipoteticamente firmado entre as partes, no qual são definidos regras e princípios moralmente corretos. Uma vez eleitos, os parceiros os utilizam para regularem acordos posteriores e determinarem a distribuição de direitos e deveres, bem como a distribuição dos benefícios advindos da cooperação. Nessa visão, os contratantes, ainda que de algum modo sejam discriminados, ou sejam menos favorecidos, podem consentir e conviver com a existência de algumas desigualdades [assimetrias] no relacionamento. Para tal, devem acreditar que estão em situação melhor do que estariam se estivessem sozinhos. Além disso, nesta perspectiva, o certo ou errado não é decidido pelo maior saldo de felicidade (como ocorre no utilitarismo), mas pelo que pode ser justificado ao outro com base em princípios mutuamente aceitos (BORGES, DALL'AGNOL e DUTRA, 2003).

Como se pode deduzir, a análise compreensiva da ética é fundada na Ética da Convicção que se atém rigorosamente às regras pré-estabelecidas e aos ideais e na Ética da Responsabilidade tem como foco a decisão e deriva de uma reflexão sobre as circunstâncias e nas implicações que cada possível curso de ação apresenta. A análise compreensiva que influencia as concepções de Ética pela Administração, tradicionalmente não questiona o modelo econômico e político onde se inserem as relações entre os sujeitos.

\section{ANÁLISE DO MATERIALISMO HISTÓRICO E DIALÉTICO DE MARX}

\subsection{O PENSAMENTO DE MARX}

Na perspectiva do materialismo histórico e dialético, o entendimento das relações no modo de produção capitalista e, portanto, da moral burguesa passa pela compreensão dos pressupostos e da lógica subjacente as interações entre os sujeitos da ação, ou seja, interações das duas classes sociais complementares e antagônicas: a do capital - que quer sobreviver no mercado, aumentar seu lucro e expandir seu negócio; e a do trabalho composta dos trabalhadores que vendem sua força de trabalho mediante um salário.A lógica fundamental deste modo de produção é a centralização do capital nas mãos do proprietário que possui os bens e as ferramentas de 
trabalho e que pode comprar a ciência e a tecnologia para intensificar a geração de mais valia.

Neste sentido todas as relações estariam subordinadas a prioridade econômica para beneficiamento de uma elite que detém o controle do processo de acumulação do capital.Isto significa dizer que as relações entre patrão e empregado, patrões e patrões e empregados e empregados estão subordinadas as leis do mercado.Esta lógica se reproduz na totalidade das relações sociais (veja mundialização do capital / globalização) entre todos os habitantes do planeta e nações (as nações ricas exploram e dominam as nações pobres) e é sustentada por uma ideologia burguesa que garante o processo de alienação dos trabalhadores na materialidade de seu cotidiano.

Segundo Marx

[...] o trabalho é um processo entre o homem e a Natureza, um processo em que o homem por sua própria ação, media, regula e controla seu metabolismo com a Natureza (...). Ele põe em movimento as forças naturais pertencentes à sua corporalidade, braços e pernas, cabeça e mão, a fim de apropriar-se da matéria natural numa forma útil para sua própria vida (MARX,1985,p.149).

Para Marx o trabalho é a categoria fundante da sociabilidade humana, tendo dupla dimensão:

[...] enquanto condição de existência humana ele revela o caráter universal da atividade humana, ou seja, a necessidade natural de o homem transformar o mundo para satisfazer suas necessidades;(...) e enquanto atividade criadora de valor de uso ele se realiza e se efetiva no interior e por meio de uma forma específica de sociedade historicamente determinada (TEIXEIRA,1995, p.49).

Desta forma, observamos que o entendimento do trabalho passa pelo entendimento do que significa o trabalho de forma mais ampla e a contextualização do trabalho dentro do modo de produção capitalista e que supõe a existência de duas classes sociais complementares (o capital precisa do trabalho e vice-versa) e com interesses antagônicos (o capital quer aumentar seu lucro e o trabalho quer melhorar as suas condições de existência).

Para Lessa (2002), de acordo com Marx, existe a necessidade de distinguir o que significa (a) o trabalho concreto e (b) o trabalho abstrato: trabalho concreto - "é uma atividade de transformação do real pela qual o 
homem constrói, concomitantemente, a si próprio como indivíduo e a totalidade social do qual é partícipe" (LESSA, 2002, p.28); e trabalho abstrato -

é uma atividade social mensurada pelo tempo de serviço socialmente necessário e produtor de mais-valia. Corresponde à submissão dos homens ao mercado capitalista, forma social que nos transforma a todos em 'coisas' (reificação) e articula nossas vidas pelo fetichismo da mercadoria (LESSA, 2002, p.28).

Segundo ainda Teixeira, em concordância com Marx,

quem se põe a observar a sociedade capitalista, percebe que ela é fundada em relações comerciais entre os indivíduos, cujos interesses privados, particulares é o que os une e os leva a se relacionarem entre si. É no mundo das mercadorias, no mundo do mercado, e por meio dele que se tecem as relações entre os homens (TEIXEIRA, 1995, p.122).

Portanto é fundamental compreender que o mundo da experiência vivido pelos homens, onde ocorre a circulação de mercadorias, é apenas a aparência das relações de classe construídas no modo de produção capitalista. Um modo de produção baseado na sociedade de classes: a classe capitalista, que detém o capital, os objetos de trabalho e os meios de produção e que explora o trabalho para obter mais-valia, e a classe trabalhadora, que vende sua força de trabalho. A força de trabalho é assim "uma mercadoria que tem o dom de criar valor maior do que nela está contido" (TEIXEIRA, 1995, p.132).

Para Marx os fenômenos peculiares do processo de trabalho capitalista são:

a) "o trabalhador trabalha sob o controle do capitalista a quem pertence seu trabalho. 0 capitalista cuida de que o trabalho se realize em ordem e os meios de produção sejam empregados conforme seus fins, portanto, que não seja desperdiçada matériaprima e que o instrumento de trabalho seja preservado". (MARX,1982,p.154); e

b) o produto do trabalho "é propriedade do capitalista, e não do produtor direto, do trabalhador" (MARX,1982,p.149).

Esta forma de divisão do trabalho fornece a lógica do modelo que se organiza para acumular capital nas mãos da classe burguesa, já que "o capitalista, mediante a compra da força de trabalho, incorporou o próprio trabalho, como fermento vivo, aos elementos mortos constitutivos do produto, que lhe pertencem igualmente" (MARX, 1982, p.154). "O produto - a propriedade do capitalista - é um valor de uso" (MARX, 1982, p.155), portador 
de um valor de troca ou seja, "um artigo destinado a venda, uma mercadoria" (MARX, 1982, p.155). Uma mercadoria

"cujo valor seja mais alto que a soma dos valores das mercadorias exigidas para produzi-la,os meios de produção e a força de trabalho, para as quais adiantou seu bom dinheiro no mercado" (MARX,1982,p.155).

Assim, o capitalista, ao explorar o trabalho, quer produzir valor de uso, valor, mercadoria e mais-valia.

\section{2 "O AQUI E AGORA" COMO ESPAÇO DA MORAL BURGUESA}

Partindo do pressuposto de que o contexto onde se inserem as relações de negócio ocorrem no modelo de produção capitalista e que as relações entre os parceiros de negócios, atores sociais, reproduzem a lógica do modelo macro-econômico alguns dados merecem reflexão.

No final de 2005 o Banco Mundial publicou a classificação das economias do mundo de acordo com quadro a seguir.

\begin{tabular}{|c|c|c|c|}
\hline $\begin{array}{l}\text { Valor do } \\
\text { PIB - total } \\
\text { (milhões de } \\
\text { US\$) }\end{array}$ & $\begin{array}{c}\text { Total } \\
\text { de } \\
\text { paíse } \\
s\end{array}$ & $\%$ & Principais países \\
\hline $\begin{array}{l}\text { Acima de } \\
10.000\end{array}$ & 1 & 0,5 & USA (11.667.515) \\
\hline $\begin{array}{l}\text { De } 5.001 \mathrm{a} \\
10.000\end{array}$ & - & - & - \\
\hline $\begin{array}{l}\text { De } 1.001 \mathrm{a} \\
5.000\end{array}$ & 6 & 3,0 & $\begin{array}{l}\text { Japão, Alemanha, Reino Unido, França, Itália } \\
\text { e China }\end{array}$ \\
\hline $\begin{array}{l}\text { De } 501 \\
\text { a.1.000 }\end{array}$ & 9 & 4,5 & $\begin{array}{l}\text { Espanha, Canadá, Índia, República da Coréia,, } \\
\text { México, Austrália, Brasil (14․),Federação } \\
\text { Russa e Países Baixos }\end{array}$ \\
\hline De 101 a 500 & 26 & 13,0 & $\begin{array}{l}\text { Suíça, Bélgica, Suécia, Turquia, Áustria, } \\
\text { Indonésia, África do Sul,, Arábia Saudita, } \\
\text { Noruega, Dinamarca, PolôniaGrécia, } \\
\text { Finlândia, Irlanda, Portugal, Tailândia, Hong } \\
\text { Kong/China, Irã, Argentina, Malásia, Israel, } \\
\text { Venezuela, Republica Tcheca e Singapura }\end{array}$ \\
\hline $\begin{array}{l}\text { Abaixo de } \\
500\end{array}$ & 142 & 70,0 & $\begin{array}{l}\text { Hungria, Nova Zelândia, Colômbia, Paquistão, } \\
\text { Chile, Filipinas, Algéria, Egito, România, } \\
\text { Nigéria, dentre outros. }\end{array}$ \\
\hline $\begin{array}{l}\text { PIBs não } \\
\text { Confirmados }\end{array}$ & 24 & 11,0 & $\begin{array}{l}\text { Samoa, Andorra, Bermuda, Brunei, llhas } \\
\text { Caimã, llhas do Canal, Cuba, llhas Faeroe, }\end{array}$ \\
\hline
\end{tabular}




\begin{tabular}{|c|c|c|c|}
\hline & & & Polinésia Francesa ,Groelândia, dentre outros. \\
\hline $\begin{array}{c}\text { Total de } \\
\text { Países }\end{array}$ & 203 & 100 & Outros \\
\hline
\end{tabular}

Fonte: Banco mundial

(http://www.bancomundial.org.br/index.php/content/view_document/2349.html)

Este quadro, em 2013, não tem grandes alterações segundo o Banco Mundial considerando o valor do PIB em milhões de US\$: União Européia 60.659.626, Estados Unidos 17.577.691, China 15094 025, Japão 7298 147, Alemanha 4992 908, França 3577 031, Brasil 2776 324, Reino Unido 2569 471, Itália 2417570 , Rússia 2198730 e Canadá 1850401 (http://pt.wikipedia.org/wiki/Anexo:Lista de pa\%C3\%ADses por PIB nominal)

Ou seja, as sete nações mais ricas do planeta continuarão seu processo de acumulação explorando as nações mais pobres e o trabalho assalariado.

Pelo quadro apresentado, pode-se inferir que os sete países mais ricos do mundo teriam de determinar em benefício econômico próprio os destinos do resto da humanidade em termos de política, economia, valores, acesso e utilização da ciência e tecnologia, dentre outros.

$\mathrm{E}$ como começou tudo isto? De onde vem o dinheiro que vai constituir o modelo capitalista e que fez destes países os mais ricos? Poderia ser dito que o capital necessário para iniciar a produção capitalista veio de nações e pessoas que trabalharam duro, gastaram apenas o indispensável e pouparam suas economias, entretanto a verdade histórica é que o dinheiro veio, em primeiro lugar, da combinação da existência de uma classe de trabalhadores rurais feudais sem propriedade e do comércio primitivo sustentado pela descoberta do ouro e da prata na América; da extirpação, escravização e sepultamento, nas minas, da população nativa, do saque das Índias Ocidentais; e da transformação da África num campo de caça comercial dos negros. Ou seja, veio da exploração, morte e domínio do outro. Em segundo lugar a acumulação do capital vem do sistema fabril / Revolução Industrial, que em si só, proporcionou uma acumulação maior da riqueza na medida em que o patrão foi se apropriando do trabalho não remunerado do empregado. (HUBERMAN, 1986) 
Hoje vem dos grandes capitais financeiros e fundos de pensão. A forma como ele, o capital, vem sendo obtido ao longo da história tem também a marca da guerra, da morte, do roubo, da exclusão e da fome de milhões de habitantes do planeta terra, dividido entre hemisfério norte que possui o maior percentual do dinheiro do mundo e hemisfério sul que possui o maior percentual da população mundial.

Para entender o capitalismo, e sua "ética" ou moral, não é possível ver uma nação de forma isolada, só se encontra um eixo de compreensão na totalidade, na história, na luta de classe, no desvendamento da ideologia burguesa, no entendimento dos mecanismos de reprodução do modelo em todas as dimensões da realidade, na materialidade cotidiana e nos processos de alienação.

Parece que em todas as sociedades humanas a verdadeira Ética ainda existe como um ideal, sobraria a moral, no caso uma moral burguesa, referenciando os comportamentos. Ainda é possível a moral?

\section{O CONFRONTO DA ANÁLISE COMPREENSIVA COM A ANÁLISE DO MATERIALISMO DIALÉTICO}

O confronto entre a análise positivista / compreensiva de Weber, autor fundante da Administração e que, portanto, oferece subsídios para entendimento das questões administrativas e de negócios; e a análise do materialismo dialético, uma das perspectivas de análise da Filosofia moderna, se dá, a partir de alguns pontos fundamentais.

Quadro 3: Análise compreensiva e análise do materialismo dialético

\begin{tabular}{|l|l|l|}
\hline & Análise Compreensiva & $\begin{array}{l}\text { Análise do Materialismo } \\
\text { Dialético }\end{array}$ \\
\hline $\begin{array}{l}\text { Natureza da } \\
\text { ciência social }\end{array}$ & $\begin{array}{l}\text { Compreensão interpretativa } \\
\text { da ação da ação humana. } \\
\text { Livre de juízos de valor. } \\
\text { Separação total e rigorosa } \\
\text { dos juízos de fato e juízos de } \\
\text { valor }\end{array}$ & $\begin{array}{l}\text { científica. Toda a construçãa da } \\
\text { ciência está inserida num } \\
\text { contexto social, econômico e } \\
\text { político a serviço de uma classe } \\
\text { social e fundamentada numa } \\
\text { ideologia. }\end{array}$ \\
\hline $\begin{array}{l}\text { Investigação } \\
\text { científica }\end{array}$ & $\begin{array}{l}\text { Objetiva enunciar } \\
\text { proposições factuais, } \\
\text { relações de causalidade e }\end{array}$ & $\begin{array}{l}\text { Objetiva compreender as } \\
\text { contradições da realidade e } \\
\text { busca a verdade provisória e }\end{array}$ \\
\hline
\end{tabular}




\begin{tabular}{|c|c|c|}
\hline & $\begin{array}{l}\text { interpretações } \\
\text { compreensivas que sejam } \\
\text { universalmente válidas. } \\
\text { Separa o sujeito do objeto } \\
\text { de investigação.Busca a } \\
\text { verdade. }\end{array}$ & $\begin{array}{l}\text { inacabada. Faz parte integrante } \\
\text { do desenvolvimento histórico } \\
\text { do mundo dos homens. } \\
\text { Constrói-se numa relação } \\
\text { historicamente construída entre } \\
\text { o sujeito e o objeto. }\end{array}$ \\
\hline $\begin{array}{l}\text { Conceitos } \\
\text { fundamentais }\end{array}$ & $\begin{array}{l}\text { Tipo ideal / Tipos de } \\
\text { dominação legitima: } \\
\text { tradicional, racional / } \\
\text { burocrática e carismática }\end{array}$ & $\begin{array}{l}\text { Trabalho / Totalidade / } \\
\text { Reprodução / Alienaçãa / } \\
\text { Sociedade de Classe / } \\
\text { Materialismo Histórico e } \\
\text { Dialético }\end{array}$ \\
\hline Ação & $\begin{array}{l}\text { Ação racional orientada } \\
\text { mediante meios adequados } \\
\text { para objetivos e valores } \\
\text { claramente formulados e } \\
\text { logicamente consistentes; } \\
\text { ação afetiva; e emocional e } \\
\text { ação tradicional. }\end{array}$ & $\begin{array}{l}\text { Práxis reflexiva e dialética que } \\
\text { revoluciona a sociedade na } \\
\text { busca do bem da coletividade }\end{array}$ \\
\hline Lógica & Formal. & $\begin{array}{l}\text { Dialética. A dialética da história } \\
\text { é construída pelo movimento } \\
\text { das forças produtivas que } \\
\text { entram em contradição, em } \\
\text { certas épocas revolucionárias, } \\
\text { com as relações de produção. }\end{array}$ \\
\hline Indivíduo & $\begin{array}{l}\text { Ser dotado de liberdade } \\
\text { individual }\end{array}$ & $\begin{array}{l}\text { Membro de uma classe social. } \\
\text { Não é a consciência que } \\
\text { determina a realidade, mas a } \\
\text { realidade que determina a } \\
\text { consciência. }\end{array}$ \\
\hline Sociedade & Harmônica & Complexa e contraditória \\
\hline Moral & $\begin{array}{l}\text { Orientada pela razão. Não } \\
\text { acredita em valores } \\
\text { universais. Cada nação, } \\
\text { cultura e religião têm valores } \\
\text { diferentes. }\end{array}$ & $\begin{array}{l}\text { Orientada pelas ideologias de } \\
\text { classe: moral burguesa ou } \\
\text { moral da classe trabalhadora. }\end{array}$ \\
\hline Ética & $\begin{array}{l}\text { Orientada pela razão: Ética } \\
\text { da Convicção / Ética da } \\
\text { Responsabilidade }\end{array}$ & $\begin{array}{l}\text { Ética Social orientada pelo bem } \\
\text { comum }\end{array}$ \\
\hline
\end{tabular}

Fonte - dos autores

A partir dos resultados obtidos por Vieira (2006) resgatamos o referencial de análise que nos possibilitou pontuar e interpretar as falas dos pesquisados: o conceito de ética e moral da filosofia clássica e moderna; a abordagem compreensiva weberiana; e a abordagem crítica marxista. Conceitos, estes, explicitados anteriormente nos itens 2,3 e 4 do presente trabalho. 
Ao analisarmos as respostas relacionadas à percepção da importância da ética na construção de relacionamentos de marketing entre atores organizacionais, percebemos que as questões éticas e morais apareceram de forma clara e consistente na fala dos atores organizacionais, mesmo porque, como mencionamos anteriormente é a ética e a moral norteadores das atividades de atores organizacionais independente de estarem ou não inseridos em um cluster de empresas de base tecnológica. Fica evidente na fala dos atores apresentados no texto de 2006 que em sua fala, os atores organizacionais colocam a ética no mesmo patamar de transparência, não deixando explicito, entretanto, qual o entendimento deles, atores, com relação à ética, enquanto algo relacionado ao conjunto da sociedade. A ética aparenta ser algo que permita o aprofundamento da relação indivíduo versos indivíduo. Outras sinalizações são importantes de serem pontuadas como o fato de afirmarem a importância de terem regras claras sobre a atuação dos concorrentes e parceiros no mercado e em segundo as regras de convivência, próprias da moral.

Neste ponto, nos perguntamos se é possível o exercício da Ética dentro do Capitalismo? O que está se convencionando chamar de ética na Administração não seria uma moral datada histórica e espacialmente? Existe uma "ética" que não seja social?Os conceitos de Administração e de Marketing dão conta dos problemas gerados no campo de sua própria ação?

Considerando que o microcosmo dos relacionamentos reproduz a totalidade do modelo econômico e político vigente, observamos que vivemos um momento de grande impasse onde a grande discussão social tem como foco à Ética das nações, dos governantes, das relações internacionais, dos sujeitos dentro das organizações, dos políticos e do povo em geral. As pesquisas internacionais apontam corrupção em todas as grandes nações do mundo. No ranking da corrupção do comércio internacional, por exemplo, temos como notas aplicadas às respostas das empresas que trabalham com companhias ou agentes de exportação estrangeiros, o que se segue, variando de zero a dez: 10. Suíça - 7.81; 20. Suécia - 7.62; 3o. Austrália - 7.59; 40.Áustria - 7.50; 5o. Canadá - 7.46; 6o. Grã-Bretanha - 7.39; 7o. Alemanha 7.34; 8o.Holanda - 7.28; 9o.Bélgica - 7.2; 9o. EUA - 7.22; 110. Japão - 7.10; 12o. Cingapura - 6.78; 13o. Espanha - 6.63; 140. Emirados Árabes - 6.62; 160. 
França - 6.50; 16o. Portugal - 6.47;17o. México - 6.45;18․ Hong Kong - 6.01; 18‥ Israel - 6.01; 20․ Itália - 5.94; 210. Coréia do Sul - 5.83; 22o. Arábia Saudita - 5.75; 23o. Brasil - 5.65; 24o. África do Sul - 5.61; 25o. Malásia - 5.59; 26o. Taiwan - 5.41; 27o. Turquia - 5.23; 28o. Rússia - 5.16; 29o. China - 4.94; e 30o. Índia - 4.62 (FONTE: www.federasul.com.br). Como se pode observar, nenhum país mencionado, por mais "civilizado" que seja, conseguiu nota acima de oito.

Desta forma, retornamos reflexão inicial: é possível o exercício da Ética dentro do capitalismo, cuja sociabilidade é fundada na priorização do dinheiro como valor supremo da vida, no ter individual e na exploração do outro? Desde os gregos, com Aristóteles, a Ética é toda arte e toda investigação, bem como toda ação e toda escolha, que visam a um bem - 0 sumo bem universal, que beneficiaria o conjunto da sociedade na conquista da felicidade.

Do ponto de vista da análise compreensiva de Weber, postura, que se pode aferir como mais facilmente aceita pela Administração, pode-se deduzir que as éticas propostas pelo autor - da responsabilidade e da convicção - não dão conta da complexidade e das contradições da realidade, na medida em que: consideram o indivíduo ou grupo de indivíduos, enquanto tal; e tem como pressuposto uma sociedade harmônica. O não questionamento das interações sociais, políticas, econômicas e humanas em sua totalidade e materialidade esvazia esta análise.

Já da perspectiva da análise do materialismo dialético de Marx, podemos supor que capitalismo e ética são incompatíveis, na medida em que atuam a partir de pressupostos contrários. Pressupostos que orientam desde as políticas internacionais até o agir humano no cotidiano da vida material, emocional e espiritual em todas as suas dimensões amorosas, profissionais e sociais. No capitalismo quem tem o dinheiro tem o poder e só isto vale. $O$ máximo que é possível, neste tipo de sociabilidade, é o exercício da moral, enquanto um conjunto de preceitos datados e situados no tempo e no espaço.

Segundo o Laboratório de Estudos do Trabalho e Qualificação Profissional - Labor da UFC 


\begin{abstract}
"as mudanças no campo geopolítico mundial posteriores à desintegração da URSS e o fim da guerra-fria; o fim das políticas keynesianas e de bem-estar social, instaurando a hegemonia mundial do 'pensamento único'neoliberal; as drásticas alterações que ocorreram no campo econômico e nas políticas macro econômicas estatais, na área monetário-financeira e na estruturação produtiva mundializada; a reestruturação produtiva, tecnológica, gerencial e informacional que metamorfoseou a dinâmica das relações capitalistas de produção; e as drásticas mudanças ocorrentes no campo do trabalho e do emprego, que atingiram pesadamente a quantidade e a forma do emprego de força de trabalho, sua remuneração, organização classista e os direitos sociais e trabalhistas, demonstram as novas condições de precariedade e de subordinação a que foram submetidas as economias periféricas, entre os quais o Brasil e que resultaram no aumento da distância entre o poder e a riqueza nos Estados do núcleo central do Sistema e nos da sua periferia".(www.labor.ufc.br)
\end{abstract}

Estas colocações demonstram que a humanidade não está obtendo êxito na busca pelo bem comum. Assim, não só não é possível a Ética universal e atemporal dentro desta sociabilidade, como até a moral que é datada e localizada, deixa de ter sentido diante dos interesses econômicos anônimos do capital, agora, financeiro.

Para Chesnais (1994) o estilo de acumulação que personifica o "novo capitalismo" dos fins do século XX e início do século XXI e que é "dado pelas novas formas de centralização de gigantescos capitais financeiros (os fundos mútuos de pensão) cuja função é frutificar principalmente no interior da esfera financeira"(CHESNAIS, 1996, p.15). Ele observa que "é na produção que se cria riqueza, a partir da combinação social de formas de trabalho humano, de diferentes qualificações, mas é a esfera financeira que comanda, cada vez mais, a repartição e a destinação social desta riqueza" (CHESNAIS, 1996, p.15). A dinâmica das finanças alimenta-se de dois tipos diferentes de mecanismos: "inflação do valor dos ativos", ou seja, da formação do capital fictício; e das transferências eletivas de riqueza para a esfera financeira através do serviço da dívida pública e das políticas monetárias associadas a este. Desta forma, cerca de $20 \%$ do orçamento dos principais países são transferidos para a esfera financeira, quando uma parte do lucro assume a forma de rendimentos financeiros para os que vivem de aplicações. Assim, "o capital monetário (...) diante dos mercados tornou-se o 'novo Graal' dos governos" (CHESNAIS, 1996, p.15), acarretando endividamento dos Estados diante dos grandes fundos privados de aplicações, e conseqüentemente, 
dependência do governo às posições definidas pelos mercados e pelo capital monetário.

O modelo de acumulação fordista, dentro de suas contradições, havia conseguido por quase três décadas (1950/1975) desenvolver uma capacidade de assegurar estabilidade e expansão da acumulação capitalista que tinha como principais pilares:

- a predominância do trabalho assalariado formal como forma de inserção e de acesso à renda;

- um ambiente monetário estável; e a

- existência de Estados dotados de instituições suficientemente fortes para impor e disciplinar o capital privado.

A mundialização da economia de mercado, privatizada, desregulamentada e liberalizada, estaria libertando o capitalismo das regras, procedimentos e instituições, que haviam permitido a construção de um 'contrato social'- o Estado previdenciário ou Welfare State, ao mesmo tempo em que cria o desemprego estrutural, a marginalização e a decadência social. Ou seja, libera o capitalismo até da "moral", enquanto orientadora dos "bons costumes".

Outra dimensão fundamental que faz parte da crise consiste na "crise do modo de desenvolvimento", pois durante décadas o ocidente acreditou que seria possível o desenvolvimento planejado por etapas, quando países em processo de desenvolvimento eram ajudados por países mais ricos. Com as transformações tecnológicas, políticas e econômicas das últimas décadas, os países desenvolvidos, agentes externos de desenvolvimento, não estão mais interessados em sua promoção, pois o produtivismo a qualquer custo, sem atenção aos recursos naturais e a repartição do trabalho e da renda estabeleceu os seus limites sociais, políticos e geográficos. Desta forma, 0 sistema tende a se fechar sobre si mesmo, fazendo com que sua elite passe a construir fortalezas para conter os 'bárbaros' na periferia, e arame farpado em volta de seus guetos internos (CHESNAIS, 1996).

Com relação à questão - Os conceitos de Administração dão conta dos problemas gerados no campo de sua própria ação? Verifica-se que a Administração por sua especificidade de "ciência aplicada", necessita valer-se dos conhecimentos de outras ciências para construir seus próprios 
conhecimento e reformular sua ação. No caso específico da ética os conhecimentos da Filosofia tornam-se assim fundamentais.

Finalmente, segundo a Filosofia não existe ética individual "eu faço a minha parte e quem quiser que faça a sua" e sim somente existe a ética social quando todos estão comprometidos com o bem comum e isto só é possível dentro de uma nova sociabilidade. O que nos resta, enquanto construímos uma nova sociabilidade favorável ao exercício da Ética, é agirmos buscando dividir riquezas, mediante ações políticas concretas onde os trabalhadores, pobres e excluídos possam adquirir o necessário para conquistar espaços e fazer história.

\section{REFERÊNCIAS}

ARISTÓTELES. Ética a Nicômaco. São Paulo: Martin Claret, 2005.

AUSTIN, W. Justice, freedom and self-interest in intergroup relations. In: AUSTIN, W. e WORCHEL, S. (Ed.). The social psychology of intergroup relations. Belmont: Brooks/Cole, 1979. Justice, freedom and self-interest in intergroup relations, p.20-37.

BIES, R. e MOAG, J. Interactional justice: communication criteria of fairness. In: LEWICKI, R., SHEPPARD, B. e BAZERMAN, M. (Ed.). Research on Negotiation in Organizations. Connecticut: Jai Press, 1986. Interactional justice: communication criteria of fairness, p.43-55.

BIES, R. e SHAPIRO, D. Interactional fairness judgments: the influence of casual accounts. Social Justice Research, v.1, p.199-218. 1987.

BITNER, M. J., BOOMS, B. H. e TETREAULT, M. S. The service encounter: Diagnosing Favorable and Unfavorable Incidents. Journal of Marketing, v.54, n.1, p.71-84. 1990.

BORGES, M., DALL'AGNOL, D. e DUTRA, D. Ética. Rio de Janeiro: DP\&A,. 2003.

CHESNAIS, F. A mundialização do capital. São Paulo: Xamã,1996.

CHONKO, L. e HUNT, S. D. Ethics and marketing management: an empirical examination. Journal of Business Research, Aug. 1985.

DIAS, A. A. Ética e racionalidade: discutindo o problema do sujeito autônomo.

Temas em Educação, n.10, p. 63-87. 2002. 
FOLGER, R. e GREENBERG, J. Procedural Justice: An Interpretive Analysis of Personal Systems. In: ROWLAND, K. e FERRIS, G. (Ed.). Research in personal and human resources management. Greenwich: JAI Press, v.3, 1985. Procedural Justice: An Interpretive Analysis of Personal Systems, p.141183.

FOURNIER, S. e YAO, J. L. Reviving brand loyalty: A reconceptualization within the framework of consumer -- brand relationships. International Journal of Research in Marketing, v.14, n.5, p.451-472. 1997.

GREENBERG, J. e MCCARTHY, C. The interpersonal aspects of procedural justice: a new perspective in pay fairness. Labor Law Journal, v.41, Aug, p.580-585. 1990.

GUNDLACH, G. e MURPHY, P. Ethical and Legal Foundations of Relational Marketing Exchanges. Journal of Marketing, v.57, p.35-46. 1993.

HOLMLUND, M. Perceived quality in business relationships. Helsink, Finland: Swedish School of Economics and Business Administration Library. 2000.

HOSMER, L. T. Trust: the connecting link between organizational theory and philosophical ethics. Academic of Management Review, v.20, n.2, p.379-400. 1995.

HUBERMAN, L. História da Riqueza do Homem. Rio de Janeiro: LTC,1986. HUNT, S. D. e VITELL, S. J. A general theory of marketing ethics. Journal of Macromarketing, v.6, Spring, p.5-16. 1986.

KAVALI, S. G., TZOKAS, N. X. e SAREN, M. J. Relationship marketing as an ethical approach: philosophical and managerial considerations. Management Decision, v.37, n.7, p.573. 1999.

KELLER, K. L.; MACHADO, M. Gestão Estratégica de Marcas. São Paulo: Prentice-Hall. 2006.

LESSA, S. Mundo dos Homens: trabalho e ser social. São Paulo:

Boitempo,2002.

MARX,K. Manuscritos econômico-filosóficos. Lisboa: Edições 70, 1982.

MESSICK, D. e COOK, K. Equity theory: psychological and sociological perspectives. New York: Praeger. 1983.

MORAES, A. Dialética da alteridade. $21^{\text {a }}$ Semana de Filosofia da UNICAP. Recife-PE, 2001. 56-66 p.

MURPHY, P. E., WOOD, G. e LACKZINIAC, G. R. Relationship Marketing = Etical Marketing. Research Methodologies for New Marketing, v.204, p.2140. 1996. 
OLIVEIRA, R. J. Ética e educação: a formação do homem no contexto de crise da razão. Revista Brasileira de Educação, v.2, p.33-41. 1996.

OLIVER, R. L. e SWAN, J. E. Consumer perceptions of interpersonal equity and satisfaction in transactions: a field survey approach. Journal of Marketing, v.53, p.21-35. 1989.

ROHDEN, V. Interesse da razão e liberdade. São Paulo: Ática. 1.

SROUR, R. H. Ética Empresarial. Rio de Janeiro: Elsevier, 2003.

TAKALA, T. e UUSITALO, O. An alternative view of relationship marketing: A framework for ethical analysis. European Journal of Marketing, v.30, n.2, p.45. 1996.

TEIXEIRA, F. J. S. Pensando com Marx.São Paulo: Ensaio, 1995.

VANCOURT, R. Kant. Lisboa: Edições 70. 1987.

VIEIRA, R. S. G. Ético, Ser ou não Ser? Seria esta uma questão? Anais Encontro da Associação Nacional de Programas de Pós-graduação em Administração (ENANPAD), 2006.

WEBER,Max. Lê Savant et le Polítique. Paris: Union Générale d'Éditions,1959.

\footnotetext{
${ }^{1}$ Lydia Maria Pinto Brito. Iydiampbrito@yahoo.com.br. Mestre em Sociologia e doutora em Educação pela UFC. Professora do Mestrado em Administração da Universidade Potiguar .UNP.RN.

${ }^{2}$ Ricardo Sérgio Gomes Vieira. rgvieira@gmail.com. Mestre e doutor em Administração pela Universidade Federal de Pernambuco. Professor da Universidade Federal de Pernambuco.
}

RECEBIDO EM: outubro/2013

APROVADO EM: novembro/2013 